\title{
Severe service valves for applications with high percentages of solids
}

\author{
R Waters CGIS, Canada
}

\begin{abstract}
The technology behind industrial applications such as fluids with high percentage solids continues to evolve, as do the corresponding regulations and specifications that ensure the safety of workers and the environment. Valves make up key aspects of this technology and often represent the single point of failure for entire operations. More often than not, the valves being used in high percentage solids applications are known as severe service valves (SSVs) due to their ability to withstand extreme conditions. Most experts agree that SSVs are identified by applications, and that these applications are challenging to the valve's ability to provide a minimum acceptable level of performance over a minimum acceptable duration. This paper serves to determine what the minimum requirements are for SSVs in high percentage solids applications specifically concentrating on paste and thickened tailings.
\end{abstract}

Keywords: abrasion, erosion, tight shut-off, severe service valves, commodity valves, concentrate, general purpose valves, guided shear gates (GSG), high velocity oxygen fuel (HVOF), metal seated ball valves (MSBV), paste, slurry, thickened tailings

\section{Introduction}

Mining and mineral processing have been going on for millennia, and processes have been evolving constantly to accommodate more efficiencies, safeties and economies. Specialised equipment, including process piping, has been designed to ensure success. Curiously, one of the general equipment subjects has been a laggard in its evolution - the valve.

While valves have also been around for thousands of years with the Romans fabricating basic plug valves for water transportation, the Industrial Revolution was the catalyst for the development of most of the valve types in existence today. However, these earlier valve types, such as gates, globes and check valves, were not suited to many of the more challenging applications that have developed. These spawned more differentiation of valve technologies and provided an increasingly varied number of valve solutions. Industry saw the development of the ball valve, the knife gate valve, the ram piston valve and the various types of butterfly valves now available to meet each specific need.

Compared to other commodity groups, valves themselves have been slow to advance their abilities. Can one name a single valve technology that is more recent than the 1960s or 1970s? Yes, we have advances in materials and trims but the modern basic valve types are still based on mid-20th Century inventions. These include the floating and trunnion ball valves, conventional, through-gate, push-through and guided shear gate (GSG) forms of the knife gate, and the sleeve-lined or lubricated plug valves.

The valve industry has also been slow to develop objective definitions of valve performance, which has handicapped designers and users from selecting the most effective valve types for their services. All valves perform only two functions: they either control or isolate flow. Experience has taught us that a single valve should not be used for both of those duties. Within each application requirement of control or isolation, three criticalities have been generally identified - commodity, general purpose and severe service.

Each of these three criticalities has been poorly separated because of the subjective nature of their definitions. In order to rectify this, several individuals in the valve industry, including the author, sought to clearly and objectively define each category. Under a specific request, the Manufacturers Standardization 
Society (MSS) of the Valve and Fittings Industry started a program to determine the minimum requirements a valve should be able to meet when faced with extreme conditions, whether from pressure, temperature, toxicity, solids, usage or a combination of those challenges. In addition, MSS sought to provide objective definitions whereby interested parties could subject their own valves to a number of thresholds that identify severe service valves (SSV) and provide further guidance when they are so defined.

Valves used in applications with high percentages of solids are nearly always of the SSV kind.

\section{Valve type definition}

\subsection{Commodity valve: little or no consequence on valve not performing}

Commodity valves are generally those that are bought in bulk at the lowest possible price, characterised by the following:

- The valves do not need to provide tight isolation (leaks past the seat and/or to the environment via stem or body connections are of little concern).

- Suppliers do not add any value, simply moving stock keeping units.

- Nearly always available from stock inventory.

- Many competitors and importers, mainly Chinese or Indian manufacturers.

- Very little process data needed to supply (client knows what he or she wants).

- Valve is never repaired (it is of low value and not worth the cost to repair) and is generally replaced with the same type (replace in kind).

\subsection{General purpose valve: minor consequence from valve not performing}

General purpose valves are more expensive than commodity valves, in the median price range, and generally perform well in most applications for a reasonable amount of time, and are characterised by:

- Some quantity inventoried by users (often most available from supplier stock inventory).

- Repairs with factory parts available to make new again at $<60 \%$ of new cost.

- Fewer competitors (more North American, European, Korean and Japanese manufacturers).

- More process data needed to properly supply (client has an idea of what they want).

- Valve is of higher quality, higher cost and often worth the cost to repair. Purchase price does not have the same significance it does with commodity valves.

\subsection{Severe service valve: serious consequence when valve does not perform}

Severe service valves have a high cost because of the need for fit-for-purpose designs with the longest installed life requirements that can handle severe service applications. These valves are used in critical applications such that, when the valve does not perform, serious consequences may result:

- Unscheduled plant shut-downs.

- Unacceptable leakage downstream and/or to atmosphere.

- Loss of production.

Other considerations are:

- Operating expense is an important factor.

- Significant data is required to make the best selection. 
- Rarely in stock (unless a partnership is in place).

- All process data and much more information is required to make the proper selection.

- Products supplied from North America, Europe, South Korea and Japan only

- Valve is replaced and repaired. Should this happen frequently, the application should be reviewed to determine if the correct valve technology is being used and if there are any other solutions available.

\section{$3 \quad$ Valves for fluids with high percentage solids}

Valves used in fluids with high percentages of solids (slurries) are required to operate under a variety of challenges including resistance to abrasion, erosion, blockage and scale precipitation or solidification.

Generally, we describe fluids with solids as 'slurries', that is, a semi-liquid with soluble or suspended solids. The transport fluid or liquid is typically water (at least in mining applications) and contains various concentrations or weights of solids in one or two phases (dissolved or suspended). We can give the slurries three basic differentiations:

- Light slurry $<5 \%$ solids by mass.

- Medium slurry 5-20\% solids by mass.

- Heavy slurry $>20 \%$ solids by mass.

Light slurries are typically accidental or upset condition slurries and may be more accurately thought of as 'dirty' process fluids. General purpose or even commodity valves may be able to handle these conditions adequately.

The science and art of slurry isolation valves deal exclusively with medium and heavy slurries and have evolved to now include pressure ratings from lower than $2 \mathrm{MPa}$ (ASME Class 150) to $42.5 \mathrm{MPa}$ (ASME Class 2500) and pipe and valve diameters up to $1,200 \mathrm{~mm}$.

For mineral processing applications, slurries are typically paste (thickened slurry), tailings (mineral waste) or solid concentrates like copper, iron, alumina, zinc and potash. Some processes, especially hydrometallurgical ones, contain fluids with significant dissolved solids and require specific valve designs and types to adequately operate.

As the slurry pipeline business grows and replaces previous truck, train or conveyor transportation, longer and higher pressure pipelines are being installed. The pipelines vary with length, elevation differential, (upward, downward or level flows) and slurry densities - all factors adding to a specific design that attempts to keep the solids distributed throughout the pipe as evenly as possible.

Paste pipelines are an important subset of slurry pipeline systems, and a specialised set of valves providing unique abilities is necessary to ensure the paste system operates at full efficiency and availability and prevents blockages that can idle the paste delivery, which endangers the safety and profitability of underground mines.

Very early valve types used to isolate solutions with solids were basic plug valves. These evolved to include a lubricant that could be injected to seal between the body and the plug and stop the flow. It was much later in the last century that slurry handling began to expand its piped distance and pipe size, forcing the development of a new generation of valve technologies that replaced these plug valves. This included the metal seated ball valve (MSBV) and the slurry knife gate - two of the primary valve choices for slurry isolation today. With paste systems, additional valve designs include ram piston valves, diverter valves and slurry control valves.

The world's first true MSBV was a key development. Unlike the original soft-seated floating ball valve patented by Howard Freeman of Jamesbury Inc. (who seized on the development of Polytetrafluoroethylene (PTFE or Teflon ${ }^{\mathrm{TM}}$ ) to provide 'tight' shut-off), a floating ball valve with hard metal seats replacing the soft seats wasn't the simple answer. A bright design engineer who had apprenticed with several of the world's 
steam service valve producers saw an advantage with the integral seat, where the seat was part of the body. This simple concept removed the chance of leakage or slurry packing around or behind the seat and with the advent of much harder materials, Kevin Hunt, of ValvTechnologies, designed the world's first true MSBV. Originally focusing on providing the tightest shut-off of steam (true zero leakage ( $100 \%$ isolation)), ValvTechnologies' use of chrome and tungsten carbides for the sealing components added another vast improvement over industry's hardest materials used - that is, Stellites ${ }^{\mathrm{TM}}$. Stellites at room temperature vary in hardness from Rc 42 to 44 while the carbides are orders of magnitude harder at Rc 68-72. This significant increase in hardness gave ValvTechnologies two important design advantages:

- The high hardness resisted galling so the physical load on each of the two sealing components (the ball and the integral seat) could be designed at such a high level that, when mate-lapped together with diamond paste, prevented even a small diameter gas molecule to pass - true zero leakage.

- The hardness resisted or eliminated abrasive wear from the pipeline's slurry, allowing long service life.

With this great leap of ability for slurry ball valves, the only early limiting factors were actuators powerful enough to turn the high-torque valves under their actual operating conditions. Hydraulic and electrohydraulic actuation was the solution offering $100,000 \mathrm{Nm}$ of torque and higher, and today actuators offering torques in excess of $250,000 \mathrm{Nm}$ are in service.

Concurrently with the advance of ball valve technologies, slurry knife gates arose from a need to produce a lower capital expenditure isolation valve for mining slurries. In the mid-20th Century, the Clarkson Company developed a sleeve-lined gate valve now known as the push-through knife gate valve. The original knife gate valve, patented by Stafsjo in Sweden in the 1920s (and later redeveloped in the USA for use in the pulp and paper industry on pulp slurries) was ineffective in mineral processing slurries with solids that were abrasive, erosive and packed into internal valve crevices. The Clarkson's elastomer sleeves solved that problem and became effective solutions for low-pressure, low cycle and neutral pH slurry applications.

Push-through knife gate designs use two interference fit elastomeric sleeves that are deformed by the gate when cycled. During closing, the gate is pushed through the sleeve liners and exits the bottom of the valve, forcing a discharge of the process media on each and every stroke. These discharges get larger over time, especially with cycles and higher differential pressures.

The push-through knife gate's discharges are a handicap in certain situations. It hardly mattered in benign, low-pressure slurry solutions like those found in basic mining processes in the grinding circuit, flotation or low-pressure tailings, but where the mine existed at elevations or latitudes where ambient temperatures fell below $0^{\circ} \mathrm{C}$, process $\mathrm{pH}$ was acidic or the fluid solidified, all discharges became a problem.

A fifth type of knife gate was originally invented in 1960 and featured higher pressure isolation, bidirectional zero leakage sealing, and a true cutting ability. It became known as the GSG. The GSG (or closed body shear gate) designs use a guided gate with a chisel edge that is contacted by an elastomeric or polymeric axial seat retained in as seen in Figure 1. 


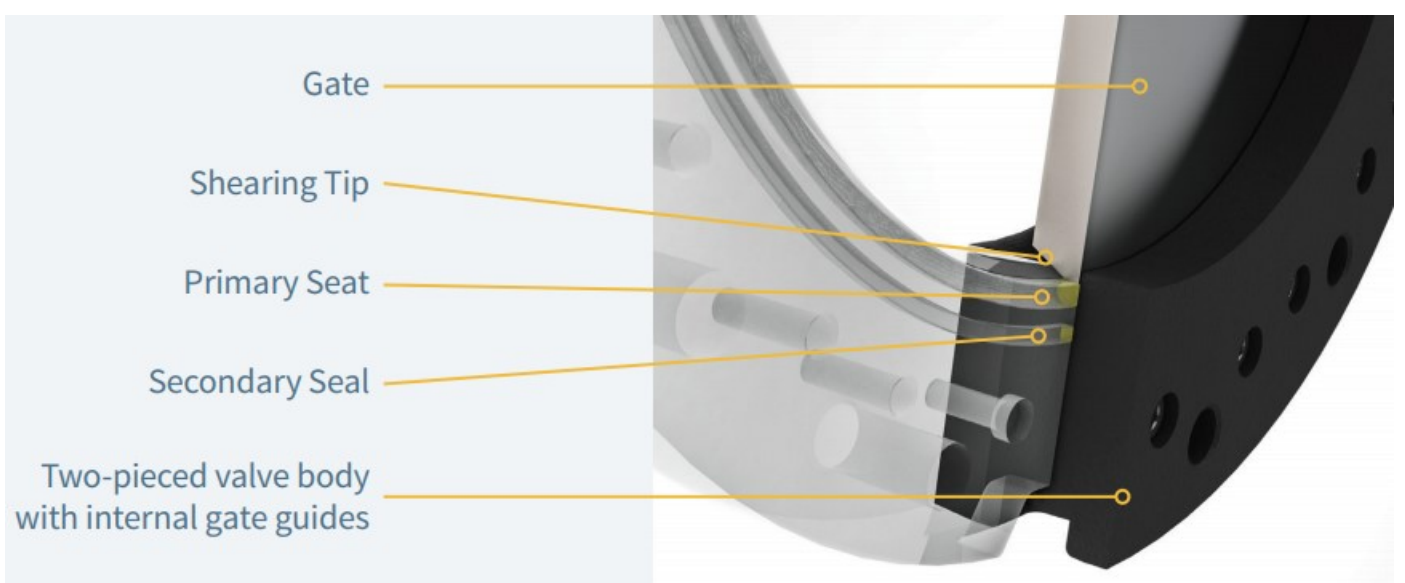

\section{Figure 1 Shear tip and bottom sealing of guided shear gate}

The need of a higher pressure slurry isolation valve for a cold climate facility led to the use and development of the highest performance type of knife gate valve, the GSG. This valve, designed in 1960 in Switzerland, differed significantly from the four other styles of knife gate valve in that it actually 'cut', using its guillotine gate tip guided between two machined body halves. The precise gate movement allowed the thrust of the valve operator or actuator to close despite solids in its way, whether scale or solid rocks. In northern Canada in 1996, the world's first ASME Class 300 (PN50) large diameter slurry knife gate valves went into service and another valve technology began to evolve and provide slurry solutions to a growing industrial need.

\section{$4 \quad$ Valve design decisions for solids}

The selection of valves for slurry systems involves several considerations:

- Abrasion of valve internals.

- Contact between the abrasive fluid and the valve components (friction, impingement, sliding, settlement, deflection).

- Increasing velocity of the solids increases erosion and erosion-abrasion-corrosion potential.

- The size, hardness, shape and concentration of the solids.

- Whether solids adhere to the internal surfaces of the valve.

- The valve's ability to operate with solids present internally.

The slurry valve has several discrete stages of existence where its vulnerability can be substantially different from its other states of position.

All isolation valves have at least four position states:

- Normally open (N/O).

- Normally closed (N/C).

- Transitioning between N/O and N/C.

- Transitioning between N/C and N/O.

Assuming that continuous positive flow is occurring, there are differences in transitioning from N/O and N/C:

- $\mathrm{N} / \mathrm{O}-\mathrm{N} / \mathrm{C}$ : increase in velocity until isolation.

- $\mathrm{N} / \mathrm{C}-\mathrm{N} / \mathrm{O}$ : decrease in velocity until fully open (except at initial opening).

Several methods used for analysis and comparison of the severity of the slurry include: 
- Hardness scales like Rockwell (B \& C), Vickers, Shore, and Brinell.

- Miller number test for slurry abrasivity (per ASTM G75-15).

- Slurry abrasion response of materials (SAR) (per ASTM G75-15).

- Particle size and distribution.

- Specific rheological investigation.

The study of flowing slurries, both in the lab and in the field, has revealed some important factors for the successful design of a slurry pipeline and, since the Wasp et al. (1977) model, other work has been done to refine and better define successful operating regimes. The following factors can also influence the design and selection of valves for use in such systems:

- The best flow regime is the one that maintains as much of the solids in suspension equally throughout the pipeline (homogeneous flow).

- Accurate definition of the critical velocity.

- All dead leg voids, steps and abrupt changes within the piping system should be avoided.

\section{$5 \quad$ Considerations for valve design and manufacture}

To ensure reliable design and selection of valves for slurry service:

- Designs need to handle the deposition of scales, fines or dewatered slurry throughout the non-flowing regions of the valve.

- Seats and seals should be made from materials that can withstand the nature of flowing slurry.

- Sealing seats should be capable of providing zero leakage under full design pressure and also with no or low differential pressure.

- Valves should have ease of operation such that plant personnel can use safe methods for cycling.

- Internal components should be protected from the potential erosion of the slurry during normal operation and also during cycling of the valve.

- Actuators, both manual and automatic, should be sized generously to overcome high viscosity slurries and the potential for precipitation of solids. Normal safety factors may be increased by a factor of 1.5-3.0x depending upon fluid characteristics.

- Valve stems should be designed to accommodate very high torque (or thrust). Maximum allowable stem torque (MAST) analysis with maximum actuator torque output is required.

- Design should account for reliability due to the need for continuous operation without the possibility of an unscheduled outage.

- Valves should be provided that become a valued asset of the plant rather than a 'consumable'.

\section{Options for low-pressure systems}

Definition of a low-pressure system is very subjective from plant to plant but typically, any system operating below $10 \mathrm{MPa}$ (ASME Class 600) is considered low pressure. The best choice for these systems would be knife gate valves with elastomeric or polymeric seats and hardened body, gate and wear rings. 


\subsection{Knife gate valve types}

While there are five distinct styles of knife gates, the push-through and GSG designs are used in slurry piping systems. See all five different styles in Figure 2. Note that all types of knife gate valves are not equally able to operate through all the same pressure ranges.

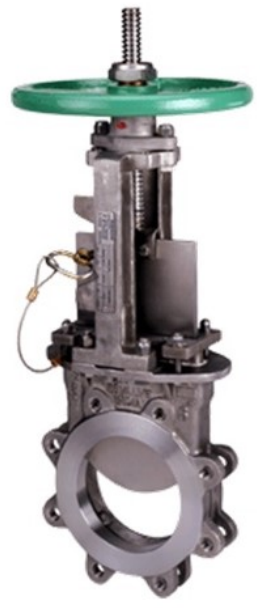

Conventional

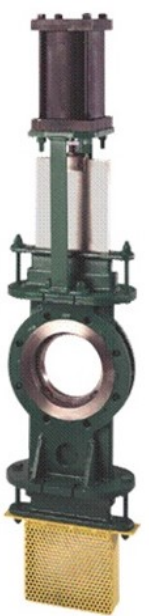

Through-Gate

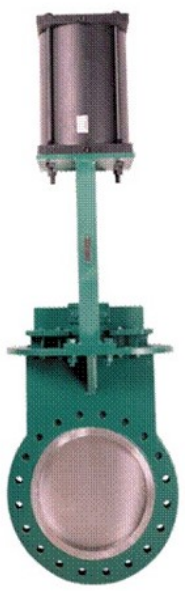

Lined

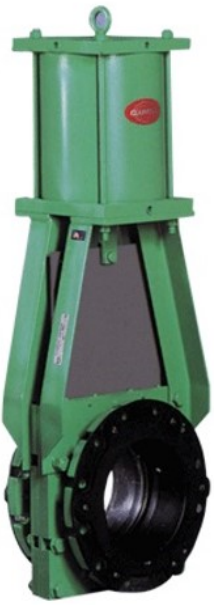

Push-Through

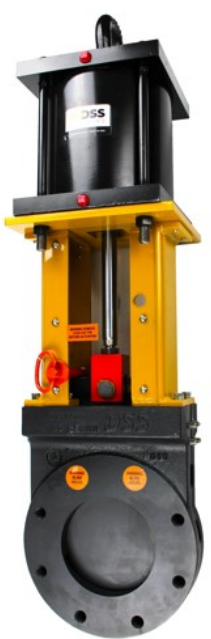

Guided Shear Gate

Figure 2 The five types of knife gate valves

\section{$7 \quad$ Application examples in low pressure}

Slurry service knife gates have been in use for over 60 years, starting on low-pressure simple systems. Over the past 20 years, experience gained from the Canadian oil sands expanded the valve designs into more challenging and higher pressure systems, now up to $15 \mathrm{MPa}$. Actual isolation valve performance in various slurries was studied at the AITF slurry test loop in 2016 (Figure 3).



Figure 3 CGIS Alberta Innovates technology futures slurry test loop (AITF) courtesy of author

The first $5 \mathrm{MPa}$ (Class 300) slurry knife gates were designed in the mid-1990s and were provided to Suncor Energy in 1996 for their tailings lines. Oil sands tailings exhibit a greater challenge for the valve design as they are formed naturally (not ground by ball or rod mills). Thus, they are far larger in particle size, are angular and have high silica content. Due to the large particle size and the higher pumping velocities $(4.5-8 \mathrm{~m} / \mathrm{s})$ required, these tailings are considered the most abrasive in the world. 
Examination of valves removed from service after their operational life had been reached led to modifications related to the basic design. The GSG was now preferred based upon its ability to handle these higher pressures. The valve's ability to provide secure containment of the process fluids, thus providing zero leakage, was critical as any water-based discharge would be subject to freezing for at least seven months in the northern location of the tailings plants.

Wear rings were used to strengthen the abrasion and erosion resistance of the bodies, and gates made from 17-4 precipitation hardened stainless steel were supplied to provide the strength and resistance needed for the slurry system. The bore of the valve was lined with chrome or tungsten carbide, applied using special overlay techniques.

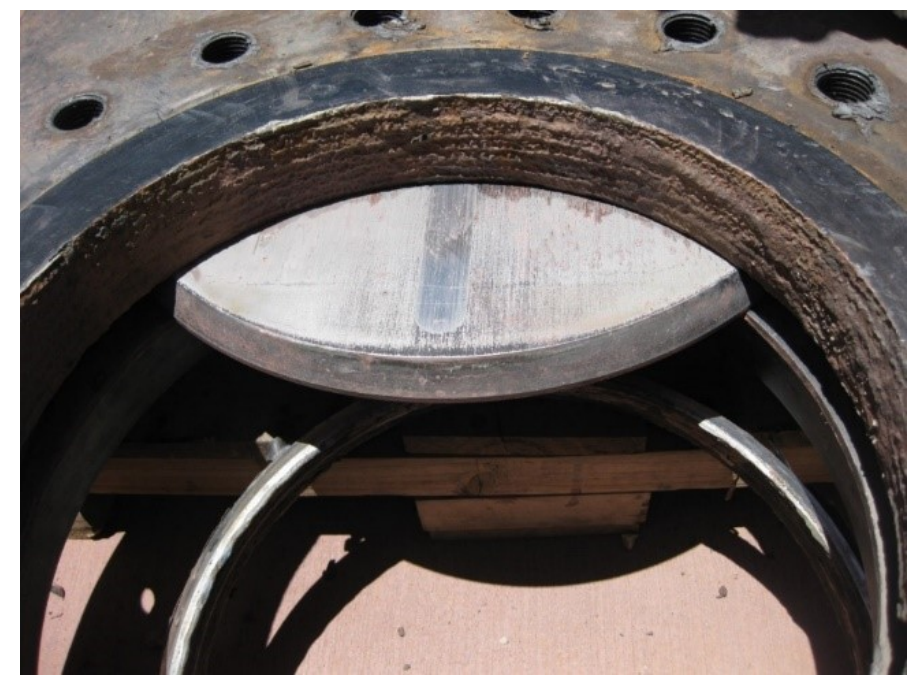

Figure 4 A six-month examination of tungsten carbide weld overlay and gate, showing no measurable wear on acidic tailings (BHP)

It is the opinion of the author that push-through knife gate valves should be limited to $2 \mathrm{MPa}$ and limited cycles due to the required thickness of the gate and its tendency to create a loss of seat elasticity during each cycle.

Guided shear gate valves have now been successfully supplied for 15 MPa paste backfill systems and are available for unidirectional or bidirectional applications. To provide longer service life, single or dual wear rings (inboard and outboard) are available in several materials including:

- Ni-Hard (Rc 59).

- Duplex SAF2507 and AISI 4140 with chrome or tungsten carbide coating (Rc 68-72).

- Ceramic (silicon nitride and partially stabilised zirconia $(\mathrm{Rc}>72)$ ).

The key design requirement of the GSG valve is to provide a shallow profile transition to reduce the effects of turbulence. The primary soft seat must be protected from the flowing slurry in order to provide zero leakage and prevent dewatering.

Guided shear gate valves have a design element that may cause some turbulence. When the gate is fully retracted in the open position, the area at the top of the waterway, within the chest and outside of the radius of the gate, is a void.

\section{Options for high-pressure systems}

High-pressure systems typically operate above $10 \mathrm{MPa}$ but the owner's choice may dictate the use of common valve types in all systems within the same plant. The best choice for these systems would be ball valves with metallic seats. 
The slurry service MSBV types are:

- Fixed seat design, where the seat is an integral part of the body.

- Fixed seat design, where the seat is welded in place.

- Fixed seat design, where the seat is retained by a bolted ring.

All slurry service MSBVs must have a fixed sealing seat and ball that are protected from the abrasive/erosive (and in some cases corrosive) nature of the slurry. Floating or trunnion type ball valves are not recommended for slurry services. Most common for abrasion-erosion resistance is a thermal spray hard coating technology such as high velocity oxygen fuel (HVOF). This method uses confined combustion and an extended nozzle to heat and accelerate the powdered carbide coating material. Typical HVOF devices operate at hypersonic gas velocities (i.e. >Mach 5). The extreme velocities provide kinetic energy, which helps produce coatings that are very dense and very well adhered in the as-sprayed condition. Figure 5 shows chrome carbide coating being robotically sprayed onto a ball.

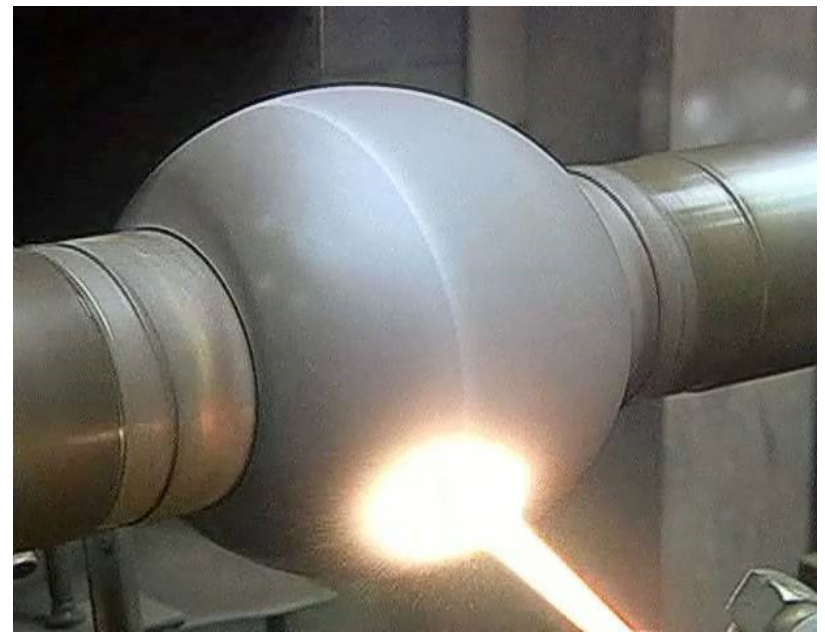

Figure 5 High velocity oxygen fuel (HVOF) coating of ball component (courtesy of ValvTechnologies)

Another method used when there is potential corrosion capability of the slurry is plasma spray. The plasma spray process uses inert gases fed past an electrode inducing the 'plasma' state of the gases. When the gases exit the nozzle of the gun apparatus and return to their normal state, a tremendous amount of heat is released. A powdered coating material is injected into the plasma 'flame' and propelled onto the substrate. Ceramic coatings are most often applied using plasma spray due to their high melting temperatures (often $\left.>1,900 C^{\circ}\right)$. Several types of ceramic coatings can be applied using plasma spray. Coatings like Titanium Dioxide and Chrome Oxide are applied with this technique. Figure 6 shows this alternative coating method.

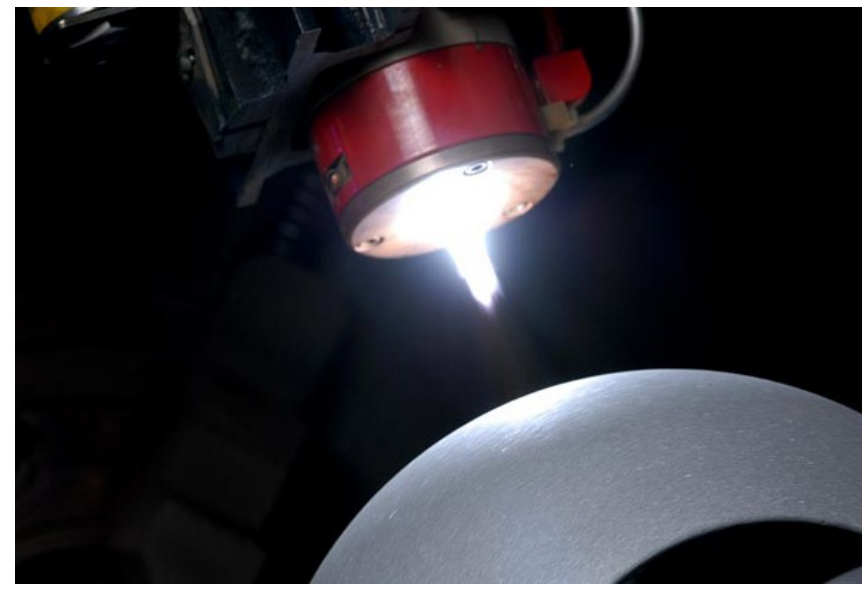

Figure 6 Plasma spray of ball component (courtesy of ValvTechnologies) 
For all thermal spray coatings, the coated parts are then lapped separately before mate lapping, where the contact surface becomes so highly polished that small particles cannot pass between these parts in a fully assembled valve.

There are also variations on the basic thermal spray coating where nanostructured coatings are used to produce a highly dense coating that is almost totally impervious to corrosion.

In all cases, the purpose of the coating is to protect the internal components of the valve from the process fluid. In some applications where abrasion is very high, even the bore of the valve is coated for protection.

\section{$9 \quad$ Application examples in paste systems}

\subsection{Paste systems}

To successfully select the correct paste valves, one must have a reasonably deep understanding of paste and its nature within the system. First and foremost, paste has cement added to the filtered tailings that solidifies in every nook and cranny, which can lead to valves not working or leading to expensive blockages.

Paste, if not mixed correctly to the geotechnical design recipe, can add to regular blockages and premature wear to pipe and valves alike. Figure 7 demonstrates a normal flowing system and one that has been blocked. Paste system pipelines vary between 75 and $250 \mathrm{~mm}$, with the most common being $200 \mathrm{~mm}$ while sizes such as $125 \mathrm{~mm}$ also feature occasionally.
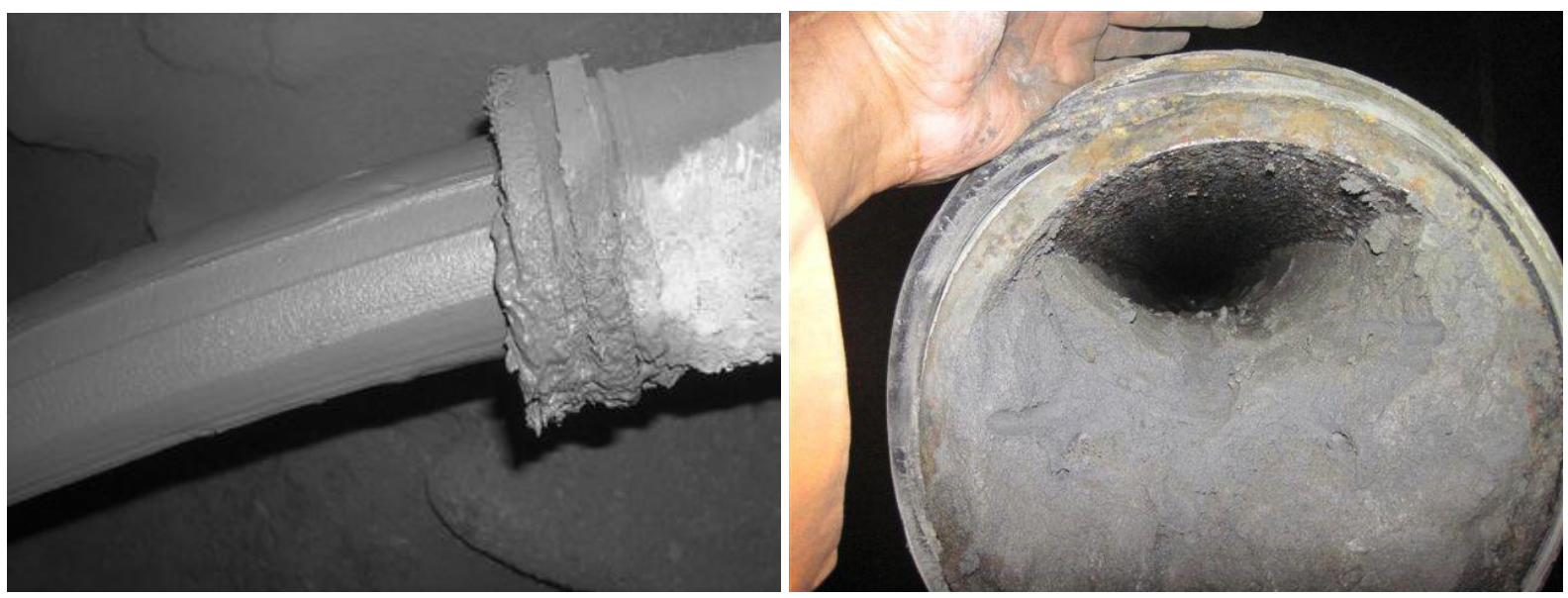

Figure 7 Paste flowing versus paste solidified in the pipeline

Paste falling underground within a borehole under gravity develops higher pressure the deeper it falls, but at the same time, it draws a higher vacuum on the upstream side. So 1 bar gravity feeds at the surface can dramatically increase to pressures above 70, 100, 120, 150, and 220 bar the deeper it falls.

Those pressures are also significantly dependent on the specific gravity of the paste mix, the angle or perpendicular nature of the borehole, solids and water content and naturally the borehole depth. Specific gravities can vary from 1.7 through to 2.4 on average, but there are obviously sites where these can be higher or lower. Heavy solids percentage in paste average between 68 and $72 \%$ with the balance being water; this is certainly much higher than many slurry concentrate transmission systems.

Final strengths of the paste vary greatly from mine to mine but the average targeted range is 5-8 MPa. Historically, they were higher (around 10-12 MPa) but that meant much more cement was needed. Cement is a very expensive commodity and due to the remote location of mines around the world, the logistical cost of delivering the cement is costly.

Some mines still use aggregate stone which can be in sizes of $15-25 \mathrm{~mm}$ but its use is not commonplace today. Typically, maximum particle sizes are not more than $1-2 \mathrm{~mm}$ in size and the paste resembles the cement mortar or tile grout you would use in your home. 
Isolation in paste pipelines is discouraged by the system designer; but in reality, mine operators need isolation for safety, pump switching, flushing and diversion.

Until recently, MSBVs were the primary isolation valve option until high-pressure GSGs were developed for isolation in 100 and 150 bar rated systems. Most ball valves were problematic in that when cycling they 'dragged' or allowed paste in behind the ball that solidified and then prevented the valve from operating the next time it needed to be used. Specific fixed seat MSBVs were designed to nullify this issue.

Paste systems deal with three distinct fluids:

- Paste.

- Flush water.

- Combination of flush water and paste.

The ideal paste system would deliver the heavy slurry paste to the stope where it would set up as the solid it was designed to become and fill the void that the mine created extracting the ore. The paste throughout the rest of the piping system would be maintained in its semi-liquid state.

In smaller mines, the paste system is likely to be a batch system operating only part of the day while in larger mines the paste system may operate $24 / 7$ for a month. In both batch durations, blockage within the piping system is to be avoided but must be designed for.

There are five valve types that are the typical for any successful paste system, as shown in Figure 8: Each has a specific duty and process requirement; isolation, flow diversion, specific flow control (soft start, variable or fixed choke), injection-break-in, and emergency dump.

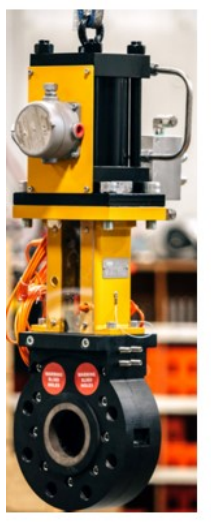

Isolation Valve

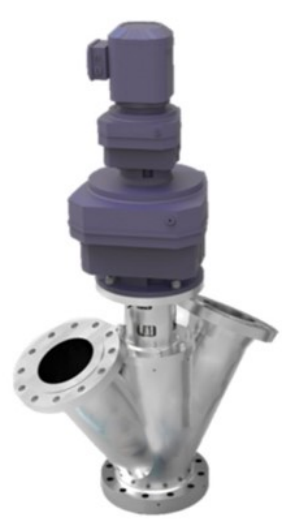

Diversion Valve

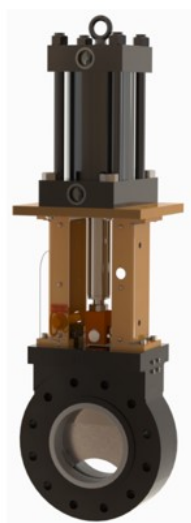

Flow Control Valve

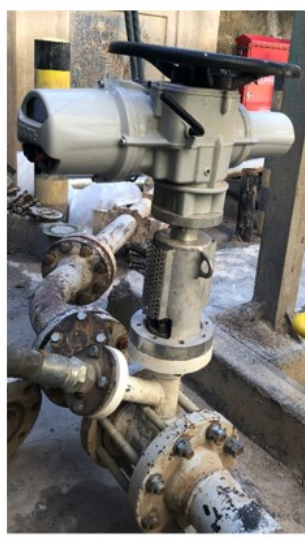

Injection Valve

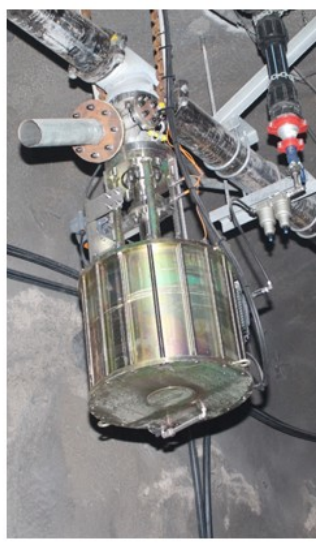

Emergency Dump Valve

Figure 8 Five typical valve types for a successful paste system

\section{Conclusion}

Applications with high percentages of solids require specific isolation valve designs and materials. Only a limited number of valve types are suitable for these applications. Advancing the abilities of older slurry valve designs like diaphragm or lubricated plug valves, GSGs and MSBVs are now the tools to use in every successful operation.

The GSG is selected for applications limited to $15 \mathrm{MPa}$ and most popular below $5 \mathrm{MPa}$ and with a much lower CAPEX than the MSBV. It is beginning to compete against the MSBV in higher pressures to its current limit especially in less arduous applications like drains and instrument isolation.

The slurry designed MSBV is used in higher pressure systems where its OPEX advantage justifies its higher CAPEX. 
By selecting the correct severe service slurry valve, maintenance can be virtually eliminated, and installed costs can be drastically reduced. True full port valves ensure an unrestricted flow path, minimise pressure drops and limit premature wear. Many valves can be manually operated but more frequently, in modern projects, are automated with pneumatic, electric, hydraulic or electro-hydraulic actuators.

Now, more than 50 years after the first significant commercial slurry pipeline, valve engineers have the advantage of many innovations that came from varying resources, including the NASA space exploration program. Using the correct valves for slurry applications is not only attributed to modern advances in the application of modern elastomers and hardened materials used in knife gate valves but also to extremely hard coatings used for the surfaces of balls and seats in slurry ball valves. Credit is also given to the advances of easy access to complex finite element analysis modelling tools used to design the valves for high pressures up to $42 \mathrm{MPa}$. Without such technological advances, the options available may have been too unreliable and too maintenance intensive to allow developers the capital approval for projects to proceed.

The effectiveness of slurry isolation valves has steadily increased. Projects and applications handling abrasive, erosive and corrosive slurries of iron, copper, zinc, phosphate, nickel and coal, as well as waste material (paste and tailings) for many minerals, have been constructed and continue to operate reliably and profitably.

Paste systems can be very reliable, safe, profitable and effective when the proper valve technology is used to prevent the blockage and inoperability of the paste system.

\section{Acknowledgements}

The author acknowledges the following companies for the use of photographs in this paper: Alberta Innovates Technology Futures, BHP Billiton, ValvTechnologies, Proeger Flow Solutions, and Paterson \& Cooke.

\section{References}

Wasp, EJ, Kenny, JP \& Gandhi, RL 1997, Solid-Liquid Flow Slurry Pipeline Transportation, Trans Tech Publications, Clausthal. 